\title{
РАЗРАБОТКА СИСТЕМЫ КОМПЬЮТЕРНОГО МОДЕЛИРОВАНИЯ И РАСЧЕТА РЕЖИМОВ СУШКИ ДРЕВЕСИНЫ
}

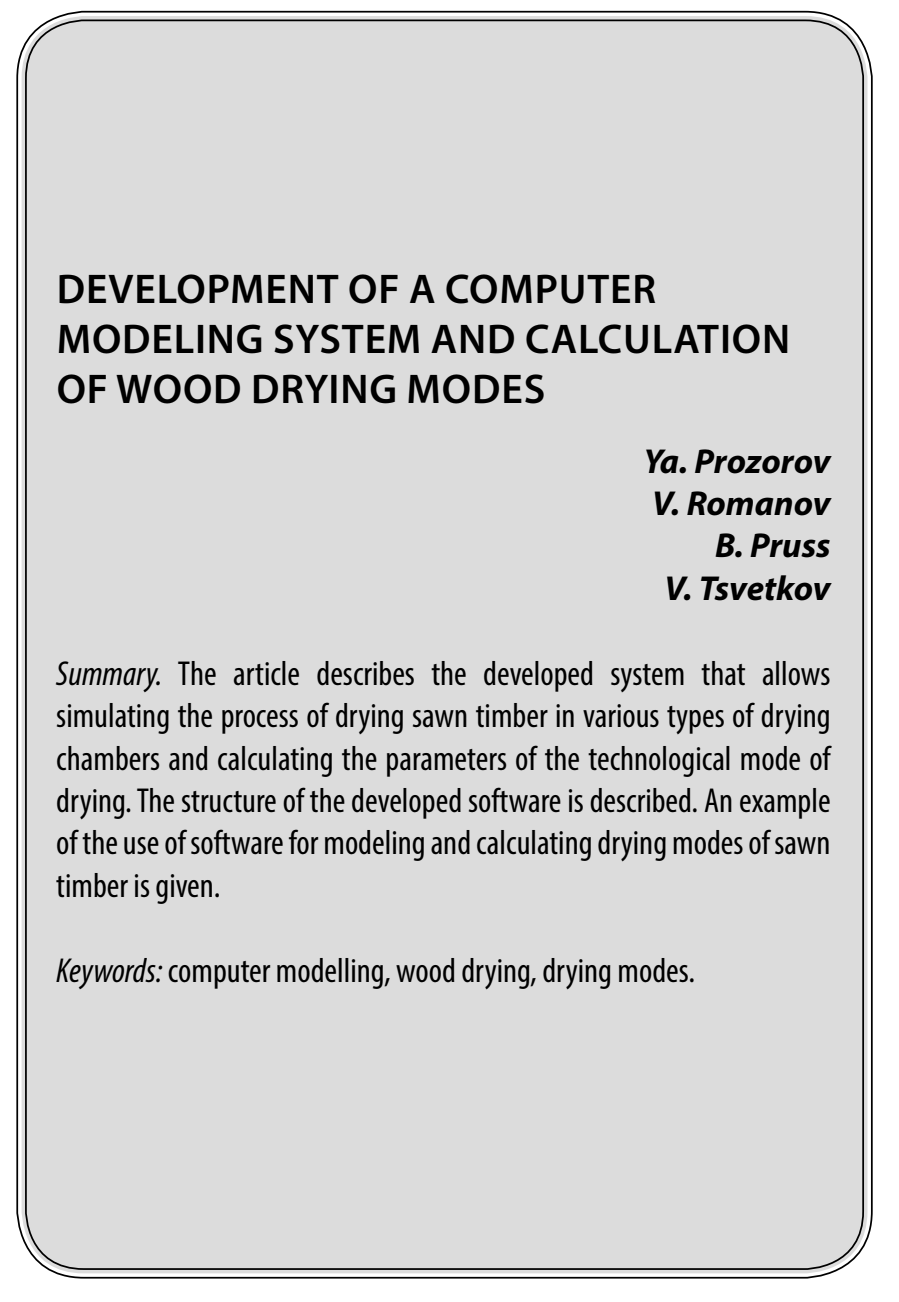

C ушкой называется процесс удаления из древесины влаги путем испарения. На сегодня применяются различные способы сушки древесины с применением сушильных камер различного типа.

К основным технологическим целям сушки древесины можно отнести: повышение прочностных характеристик получаемых пиломатериалов; предохранение от биологических поражений; снижение изменяемости размеров и форм; снижение коробления и растрескивания пиломатериалов; снижение веса. Высушенные материалы могут использоваться для последующего склеивания и отделки[1].

Удаление влаги из древесины в ходе сушки осложнено изменением ее размеров в процессе высыхания[3]. В случаях, когда процесс сушки протекает неравномер-
Прозоров Ярослав Сергеевич

К.т.н., ФГБОУ ВО «Брянский государственный технический университет», г. Брянск yprozorov@gmail.com

Романов Виктор Александрович К.т.н., дочент, ФГБОУ ВО «Брянский государственный инженерно-технологический университет», г. Брянск vromanov62@mail.ru

Прусс Борис Наумович К.т.н., дочент, ФГБОУ ВО «Брянский государственный инженерно-технологический университет», г. Брянск prussbor@gmail.com

Цветков Владислав Владимирович

ФГБОУ ВО «Брянский государственный инженернотехнологический университет», г. Брянск cvetjk3239@gmail.com

Аннотация. В статье описана разработанная система позволяющая, моделировать процесс сушки пиломатериалов в лесосушильных камерах различного типа и рассчитывать параметры технологического режима сушки. Описана структура разработанного программного обеспечения. Приведен пример использования программного обеспечения для моделирования и расчетов режимов сушки пиломатериалов.

Ключевые слова: компьютерное моделирование, сушка древесины, режимы сушки.

но, в пиломатериалах могут возникать внутренние напряжения, приводящие к короблению и растрескиванию. Исходя из этого получение высококачественного пиломатериала с требуемыми характеристиками является основной задачей сушки древесины[2].

Изделия из древесины изготовленные из влажных пиломатериалов не обладают необходимыми прочностными характеристиками и подвержены биологическим повреждениям.

Несоблюдение технологических режимов сушки древесины приводит к появлению дефектов в пиломатериалах и повышению энергетических затрат. Поэтому сушка пиломатериалов является не только длительным, но и достаточно ответственным процессом в технологии деревообработки[4]. 


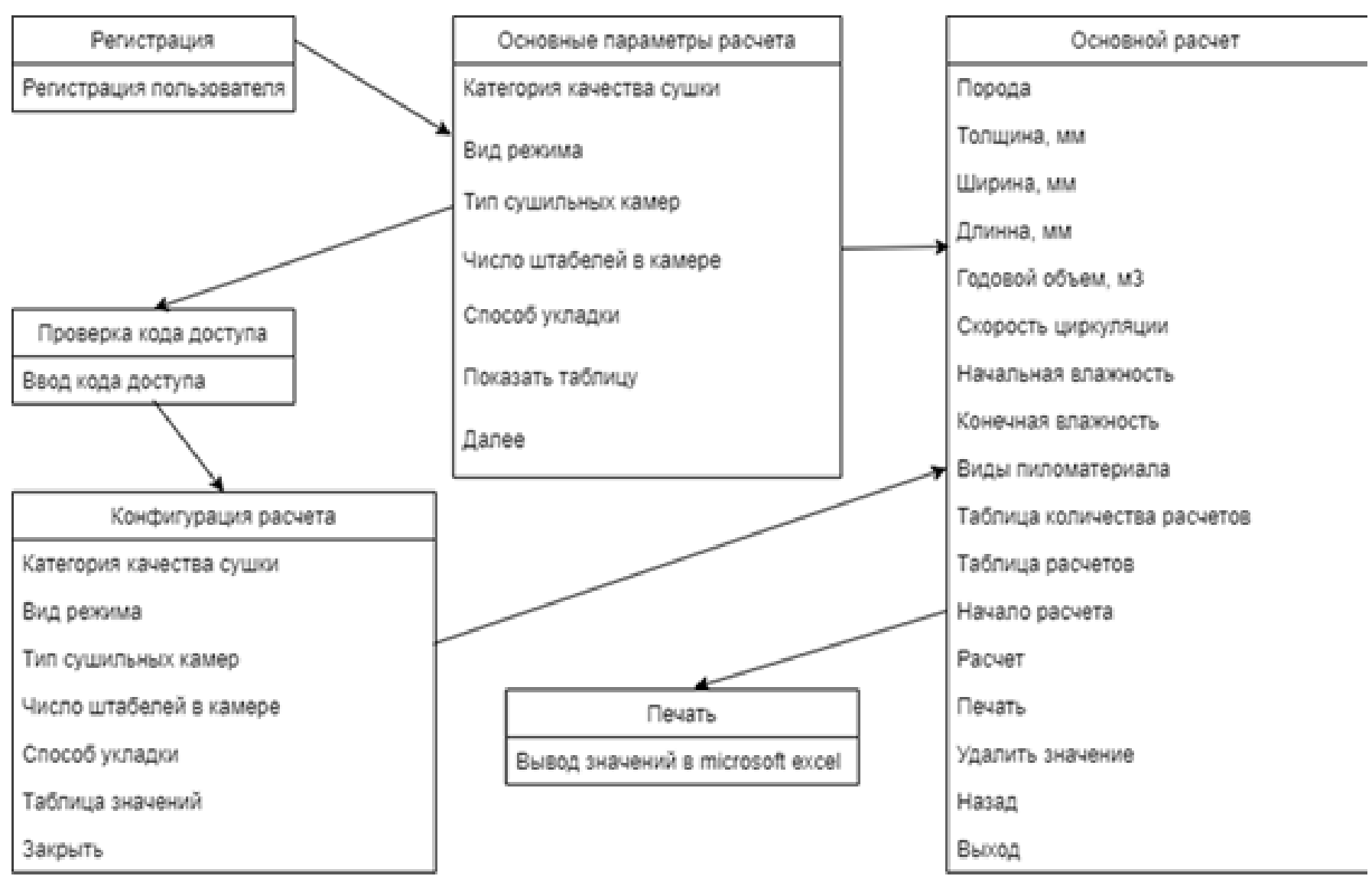

Рис. 1. Схема разрабатываемой системы компьютерного моделирования расчета режимов сушки древесины

Так как любая ошибка, допущенная на одном из этапов сушки, может привести к браку, то квалификация инженера-технолога и правильность расчетов режимов сушки древесины имеют решающее значение.

Автоматизированный расчет режимов сушки древесины не только избавит от ошибок и снизит количество брака, но и сократит само время расчетов, что является важным фактором, особенно если речь идет о промышленных масштабах.

Описанная проблема может быть решена за счет разработки информационной системы, осуществляющей расчет режимов сушки древесины. Разрабатываемая система должна включать в себя следующие функции:

- ввод параметров и корректировка режимов сушки;

- ввод параметров сушильных камер;

- список древесных пород;

- время производства;

- ввод корректных исходных данных;

- защита от ошибок при в воде данных;

- защита от изменения условно постоянной информации;
- варианты режимов сушки различного сырья;

- иметь возможность выполнять расчеты для разных древесных пород со своими исходными данными;

- возможность записи в отчет результатов расчета для различных пород;

- составление отчетов в Excel.

Общая схема разрабатываемой информационной системы представлена на рис. 1.

Для выполнения указанных выше функций, на первом этапе нами были проанализированы общие проблемы развития информационных систем, а также имеющиеся информационные системы в указанной области и установлено, что разрабатываемый программный продукт будет направлен на автоматизацию технологических расчетов при сушке древесины, выбора режимов сушки, в зависимости от древесной породы и категории сушки и других параметров, так как указанные действия не реализованы в других программных продуктах. Выполненный анализ позволил нам создать контекстную диаграмму разрабаты- 


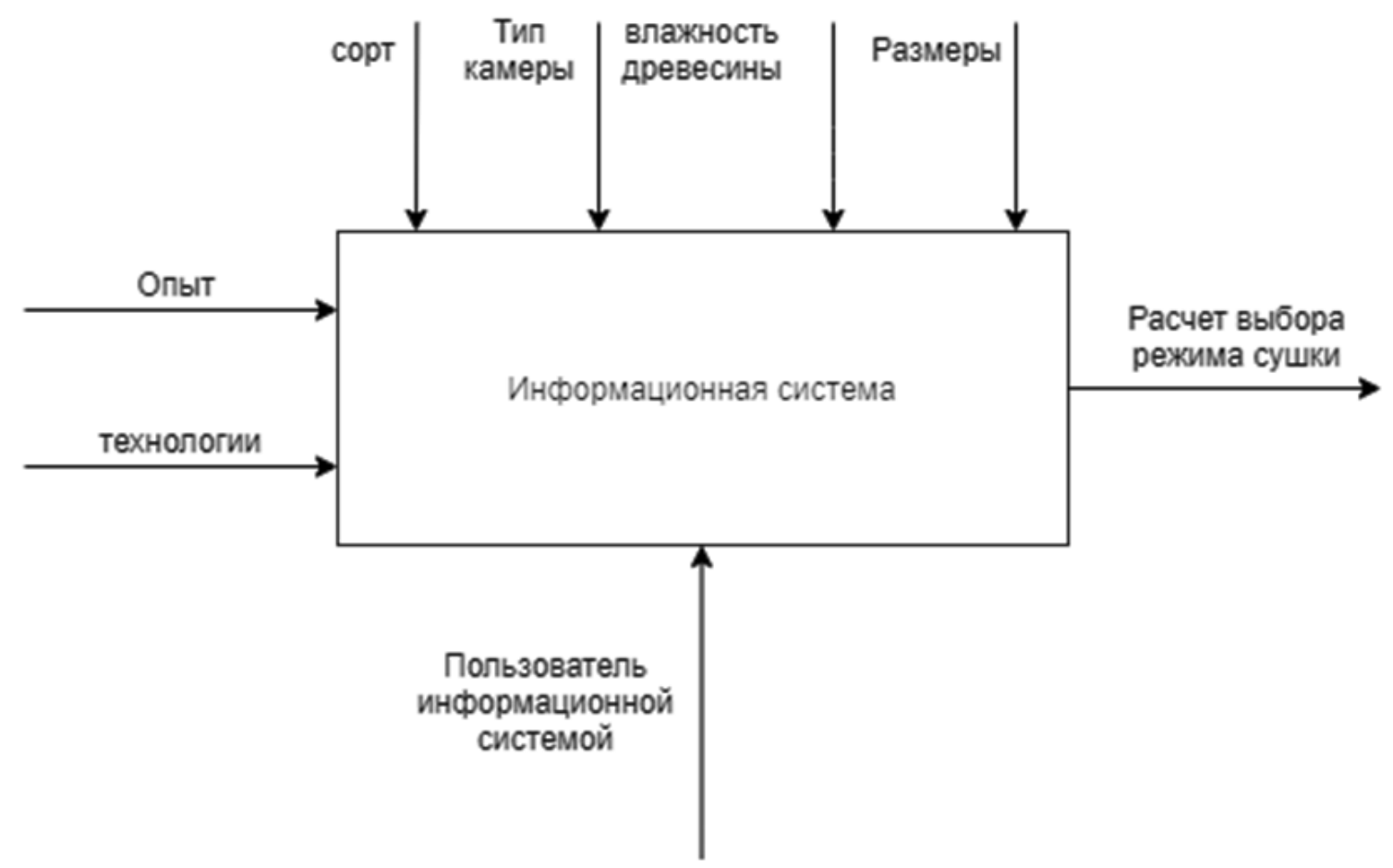

Рис. 2. Контекстная диаграмма системы

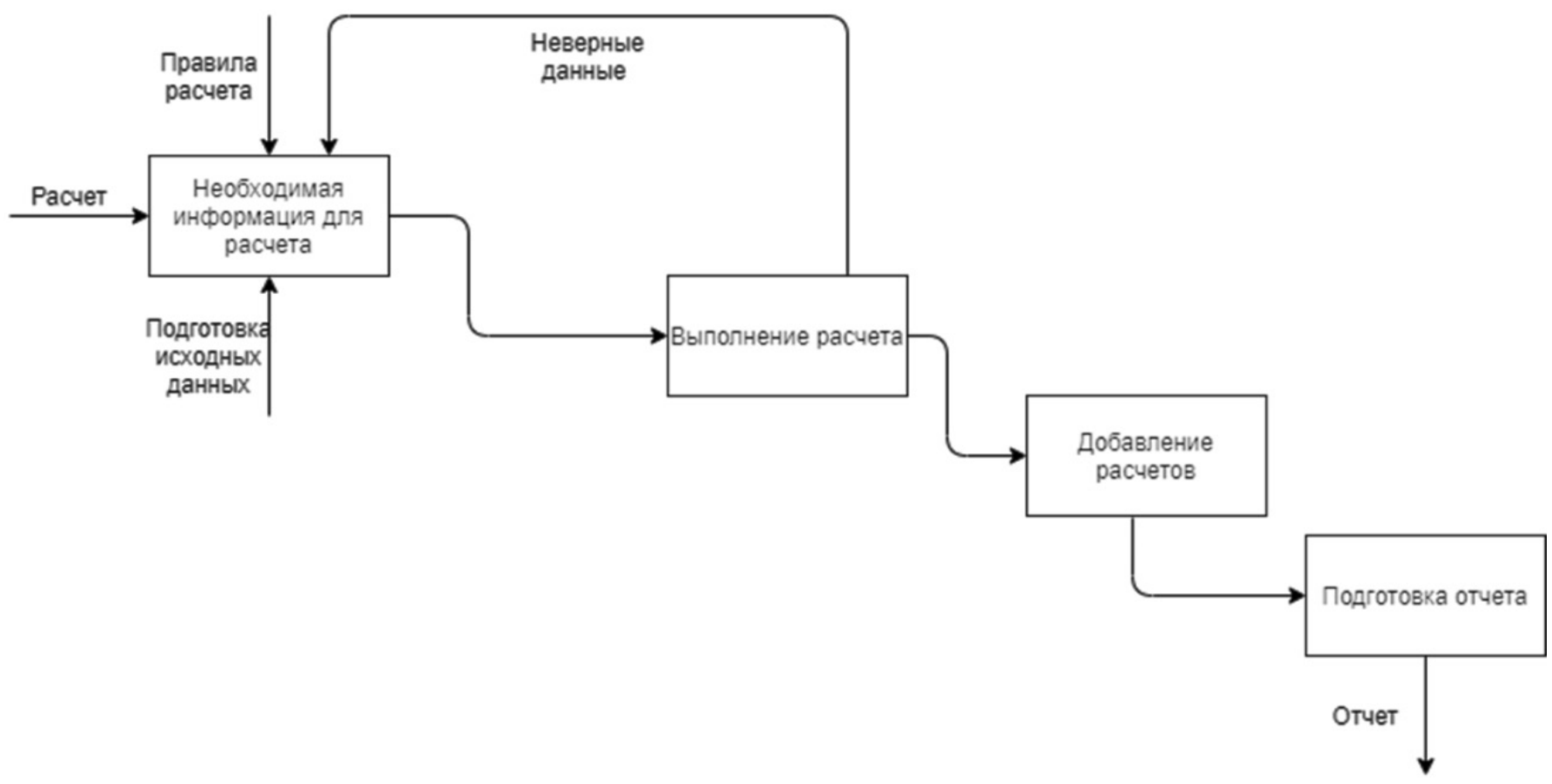

Рис. 3. Процесс расчета режимов сушки 
ваемой информационной системы, представленной на рис. 2.

Нами также был проведен подробный анализ действующих предприятий, специализирующихся на сушке древесины и использующих различные типы сушильных камер. В ходе анализа установлено, что процесс расчета режимов сушки должен состоять из корректного ввода необходимой информации, с учетом имеющихся исходных данных и правил расчета. На следующем этапе должно осуществляться выполнение расчета режимов сушки, при этом в случае ввода неправильных данных расчет осуществляться не должен. Также важным требованием должна быть возможность добавления или удаления результатов предыдущего расчета. Только после этого должно происходить формирование отчета. Процесс расчетов режимов сушки представлен на рис. 3.

Сам расчет заключается в определении продолжительности сушки в камерах периодического действия, при различных температурных процессах.

Общая продолжительность сушки тсуш, ч, включая начальный прогрев и влаготеплообработку, определяется по формуле

$$
\tau_{c y u}=\tau_{u c x} \cdot A_{p} \cdot A_{u} \cdot A_{6} \cdot A_{\kappa} \cdot A_{\partial}
$$

где $\tau_{u c x}-$ исходная продолжительность собственно сушки пиломатериалов заданной породы и размеров нормальным режимом от начальной влажности $60 \%$ до 12\% в камерах с реверсивной циркуляцией средней интенсивности (расчетная скорость сушильного агента по материалу 1 м/с), ч;

$A_{p}, A_{\psi}, A_{6}, A_{\kappa}, A_{\partial}-$ коэффициенты, учитывающие категорию режимов сушки $A_{p}$, интенсивность циркуляции Ац, начальную и конечную влажность $A_{6}$, качество сушки $A_{\kappa}$ длину материала $A_{\partial}$.

Исходную продолжительность сушки тисх находят в зависимости от породы, толщины и ширины пиломатериалов.

Для коэффициента $A_{p}$ установлены следующие значения: мягкие режимы $-A_{p}=1,70$; нормальные $-1,00$; форсированные - 0,80.

Коэффициент Ац находят в зависимости от произведения тисх囚Ар и скорости циркуляции сушильного агента по материалу шмат.

В тех случаях, когда шмат неизвестна, для приближенных предварительных расчетов ее можно принимать следующей:
- с естественной циркуляцией - 0,2 м/с;

- с циркуляцией слабой интенсивности (для камеры ЦНИИМОД-39) - 0,5 м/с;

- с циркуляцией средней интенсивности (для камер ЦНИИМОД -23, ВИАМ, эжекционные Гипродревпрома) - $1 \mathrm{~m} / \mathrm{c}$;

- с циркуляцией повышенной интенсивности (для камер ВК-4; СПЛК-2) - 2 м/с.

Для сборно-металических камер скорость циркуляции агента сушки принимается равной:

- с нереверсионной циркуляцией (для камеры СКД) $-2 \mathrm{M} / \mathrm{c}$;

- с реверсионной циркуляцией (для камер СПВ-62, ул-1, УЛ-2, СПМ-2К) - 2,5 м/с.

Коэффициент $A_{6}$, зависит от начальной $W_{H}$ и конечной $W_{\kappa}$ влажности.

Коэффициент $A_{\kappa \prime}$ учитывающий длительность влаготеплообработки и кондиционирования древесины в камере, имеет следующее значения для разных категорий качества сушки: I категория качества -1,2; || категория 1,15; III-1,05; O -1,00.

Коэффициент $A_{\partial}$ для заготовок находят в зависимости от отношения длины заготовки $L$ к ее толщине $S_{1}$. Для пиломатериалов $A_{\partial}=1$.

Объемный коэффициент заполнения штабеля $\beta_{\phi}$ для каждого сечения пиломатериалов определяется по формуле

$$
\beta_{\phi}=\beta_{B} \cdot \beta_{\text {II }} \cdot \beta_{\text {д }} \cdot \frac{100-y_{0}}{100},
$$

где $\beta_{b}, \beta_{u}, \beta_{\partial}$ - коэффициент заполнения штабеля соответственно по высоте, ширине и длине;

$Y_{o}$ - объемная усушка древесины,\%.

Величина объемной усушки определяется по формуле

$$
Y_{0}=K_{0}\left(30-W_{\kappa}\right)
$$

где $K_{o}-$ коэффициент объемной усушки;

$W_{\kappa}$ - конечная влажность пиломатериалов,\%.

Коэффициент заполнения штабеля по высоте $\beta_{6}$ зависит от толщины высушиваемого материала и толщины прокладок, и рассчитывается по формуле

$$
\beta_{B}=\frac{S}{S+S_{n p}},
$$

где $S$ - толщина высушиваемого материала, мм; $S_{n p}$ - толщина прокладок $\left(S_{n p}=25\right.$ мм). 


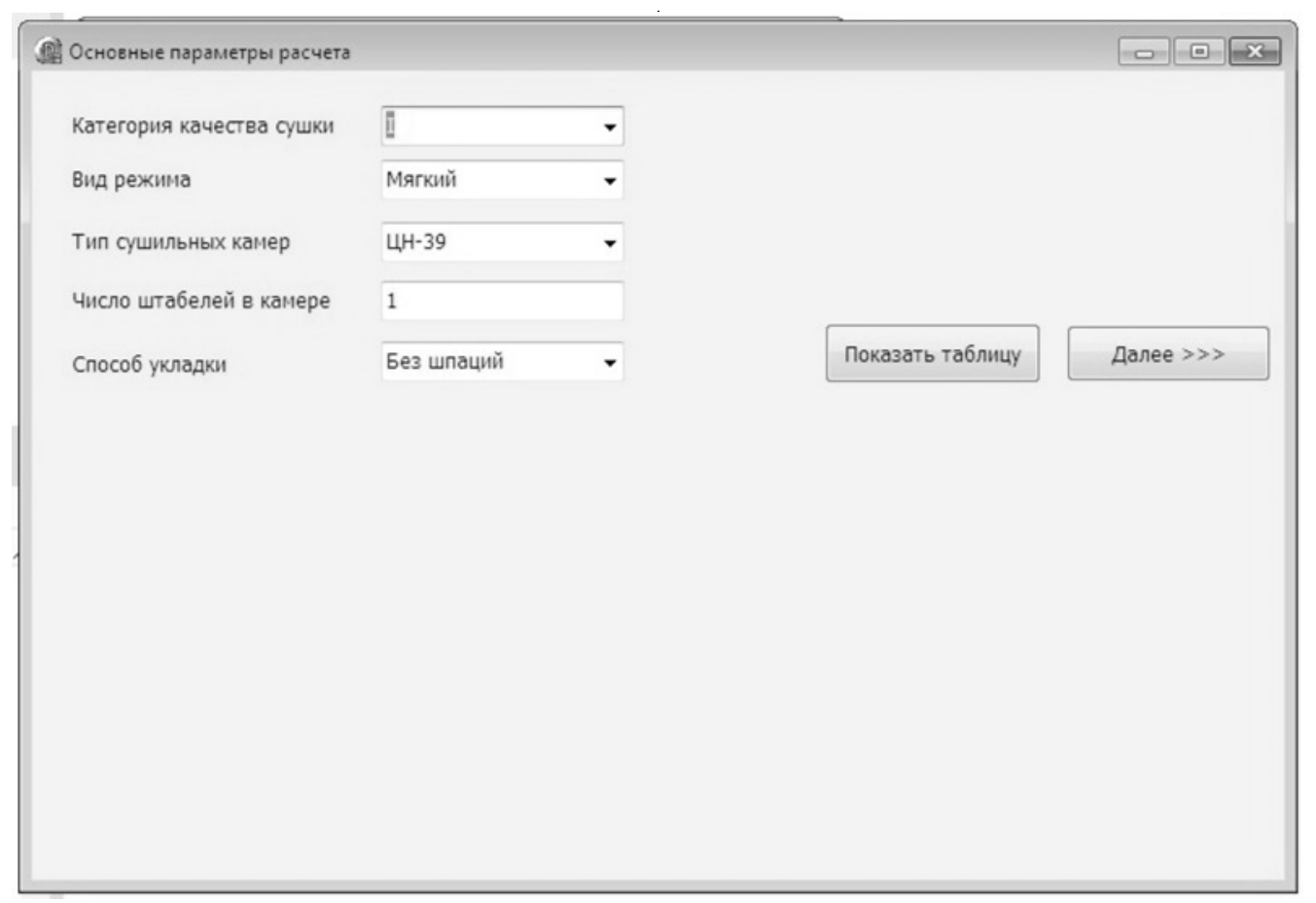

Рис. 4. Вид формы «Основные параметры расчета»

Коэффициент заполнения штабеля по ширине $\beta_{u}$ зависит от способа укладки и вида пиломатериалов.

Коэффициент заполнения штабеля по длине $\beta_{\text {д }}$ равен отношению длины пиломатериалов в штабеле к длине штабеля

$$
\beta_{\partial}=L / L_{u m}
$$

В связи с тем, что в одних и тех же камерах высушиваются пиломатериалы с различной характеристикой, производительность камеры в объеме фактически высушиваемой древесины значительно колеблется. Поэтому для учета и планирования работы лесосушильных камер вводится учетная и плановая единица - кубический метр условного материала.

Условному материалу эквивалентны сосновые обрезные доски толщиной 40 мм, шириной 150 мм, высушиваемые по II категории качества от начальной влажности $60 \%$ до конечной $12 \%$.

Объем условных пиломатериалов для каждой породы и сечения $Y$, м³ усл., определяется по формуле

$$
y=\Phi \frac{\tau_{o \sigma . \phi .}}{\beta_{\phi}} \cdot K_{n},
$$

где $\Phi$ - годовой объем пиломатериалов по каждому сечению, $\mathrm{M}^{3}$;

$\tau_{\text {об.ф }}$ - продолжительность оборота камеры, сут.;
$K_{n}$ - пересчетный коэффициент.

Продолжительность оборота камеры определяется: - для камер периодического действия

$\tau_{\text {об.ф }}=\tau_{\text {суи }}+\tau_{\text {загı }}$

где $\tau_{\text {суш }}$ - продолжительность сушки, сут.;

$\tau_{\text {заг }}$ - продолжительность загрузки и выгрузки материала,

$\tau_{\text {заг }}=0,1$ сут.;

- для камер непрерывного действия $\tau_{\text {об. }}=\tau_{c y щ}$.

Общий объем высушиваемого условного материала определяется по формуле

$$
\Sigma Y=y_{1}+y_{2}+\ldots+Y_{n}
$$

где $Y_{1}, Y_{2}, \ldots, Y_{n}$ - объем условного материала по каждой породе и сечению спецификаций, м $^{3}$ усл.

Производительность камеры в условном материале $Y_{\text {кам }}$ м $^{3}$ усл., определяется по формуле

$У_{\kappa a м}=335 \cdot K_{n} \cdot \Gamma$

где $\Gamma$ - габаритный объем всех штабелей в камере, м3, определяется по формуле

$\Gamma=n \cdot L \cdot b \cdot h$,

где $n$ - число штабелей в камере, шт.; 


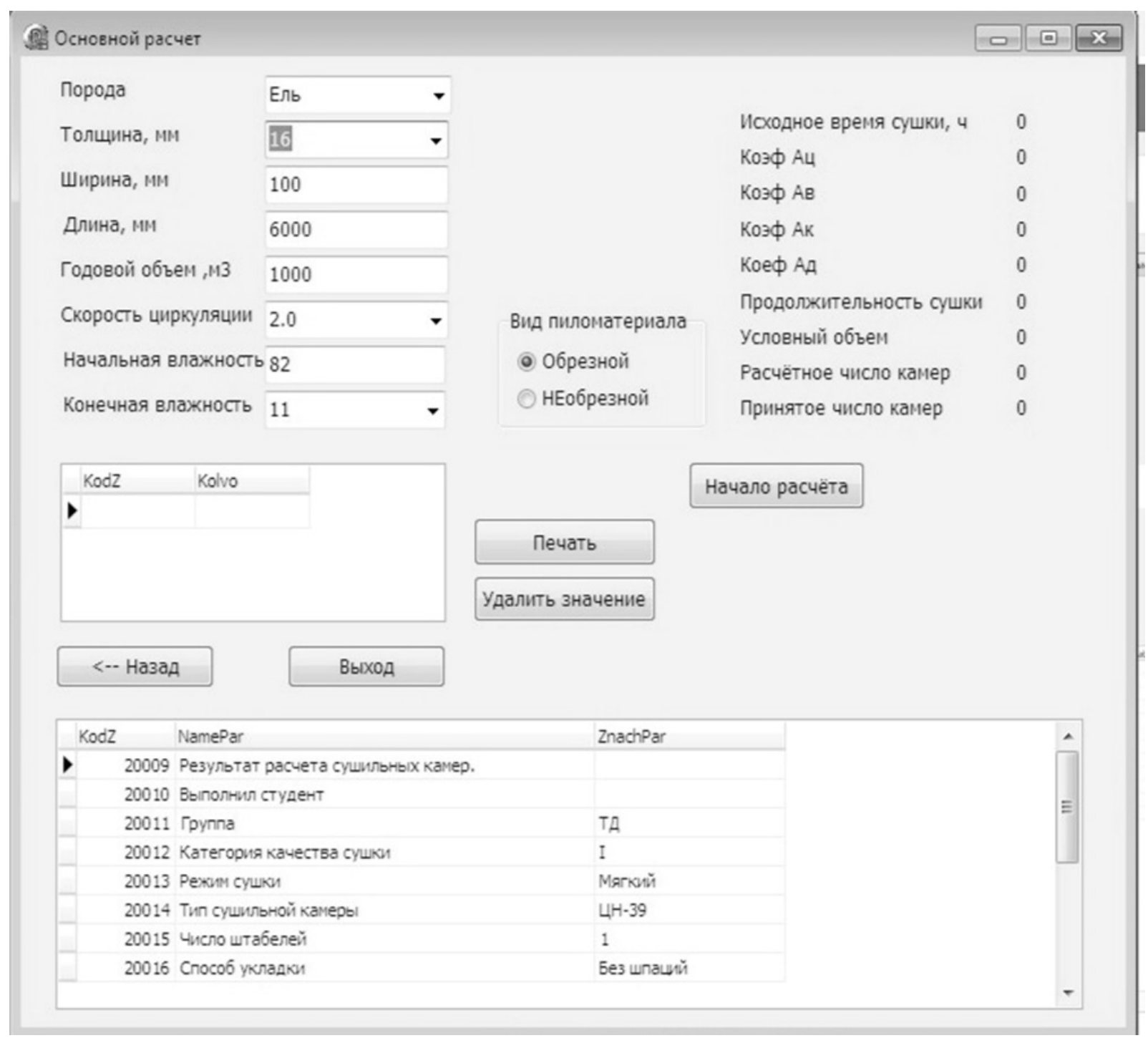

Рис. 5. Вид формы «Основной расчет»

$L, b, h-$ длина, ширина и высота штабеля, м.

Число камер $n$, шт., необходимое для высушивания годового объема пиломатериалов, определяется по формуле

$$
n=\frac{\sum y}{y_{\text {кам }}}
$$

Полученное значение округляется до целого.

Для организации расчетов нами было разработана информационная система, позволяющая моделировать и осуществлять технологический расчет режимов сушки пиломатериалов[6], интерфейс которой содержит следующие формы[5]:

- основные параметры расчета (рис. 4);

- основной расчет (рис. 5).
Форма «Основные параметры расчета» содержит поля, позволяющие выбрать: категорию качества сушки; режим сушки; тип сушильной камеры; число штабелей в камере и способ укладки древесины.

На данной форме предусмотрена возможность редактирования справочной информации или ввода новых данных. Данные функции реализованы через кнопку «Показать таблицу». При редактировании можно изменить категорию качества сушки, вид режима, тип сушильной камеры, число штабелей в камере и способ укладки.

Форма «Основной расчет» содержит в себе поля, позволяющие выбрать породу древесины, ее толщину, ширину, длину, годовой объем сушки, вид пиломатериалов и другие параметры. После выбора всех параметров осуществляется расчет требуемого количества камер 
для высушивания заданного объема пиломатериалов. В случае необходимости рассчитать другой пиломатериал следует задать новые параметры и объем.

В программе предусмотрена возможность вывода на печать результатов расчета в формате MS Excel.

Разработанная информационная система позволяет быстро и точно рассчитать параметры технологического режима сушки пиломатериалов, что в свою очередь позволит повысить качество сушки пиломатериалов, сделать выводы о состоянии технологического процесса сушки на текущий момент времени и при необходимости своевременно внести коррективы. Она может быть использована в технологических отделах на деревоперерабатывающих предприятиях, позволит автоматизировать труд инженеров, усилить контроль за соблюдением режимов сушки пиломатериалов и тем самым повысить качество выпускаемой продукции и снизить энергетические затраты.

\section{ЛИТЕРАТУРА}

1. Направления совершенствования технологии сушки пиломатериалов/ Меркелов В. М., Решин А. П. Вестник брянской государственной инженерно-технологической академии. 2005. № 1. -С. 155.

2. Управление процессом сушки оцилиндрованных бревен Лукаш А. А., Лукутцова Н. П. В сборнике: повышение эффективности процессов и аппаратов в химической и смежных отраслях промышленности. Сборник научных трудов международной научно-технической конференции, посвящённой 105-летию со дня рождения а.н. плановского. 2016. -С. 244-247.

3. К вопросу экологической сушки пилопродукции Решин А. П., Меркелов В. М. в сборнике: актуальные проблемы и перспективы развития лесопромышленного комплекса. материалы 2-й международной научно-технической конференции. 2013. с. 59-61.

4. Иследование процесса сушки древесины вишни и черешни без искусственного увлажнения в конвективных сушильных камерах периодического действия //Чернышев А.Н., Ефимова Т. В. Сборник научных трудов Sworld. 2014. т. 19. № 1. -С. 3-7.

5. Автоматизированный технологический расчет камер для сушки пиломатериалов/Прусс Б.Н., Романов В. А., Прозоров Я. С. Свидетельство о регистрации программы для ЭВМ ru 2020610401, 14.01.2020. заявка № 2019667123 от 23.12.2019.

6. Прусс Б.Н., Романов В. А., Кузнецов С. С., Жернакова В. Д. В сборнике: современные тенденции развития фундаментальных и прикладных наук. всероссийская научно-практическая конференция с международным участием. под редакцией С. А. Коньшаковой. 2019. -С. 198-202.

○ Прозоров Ярослав Сергеевич (yprozorov@gmail.com ), Романов Виктор Александрович (vromanov62@mail.ru ), Прусс Борис Наумович ( prussbor@gmail.com ), Цветков Владислав Владимирович ( cvetjk3239@gmail.com ).

Журнал «Современная наука: актуальные проблемы теории и практики» 